\title{
STRATEGI BERSAING DI DALAM INDUSTRI PERANCAH DAN BEKISTING SISTEM DENGAN MENGGUNAKAN METODE KANVAS MODEL BISNIS. STUDI KASUS : PT. BETON PERKASA WIJAKSANA
}

\author{
Argi Thaufani ${ }^{1)}$,Mohammad Hamsal ${ }^{2)}$ \\ ${ }^{1,2}$ Universitas Mercu Buana, Jakarta, Indonesia \\ E-Mail: arghee.tha@gmail.com
}

\begin{abstract}
A b s tract
Business competition, changes in consumer tastes, economic and social changes led to various challenges and opportunities faced by PT. Beton Perkasa Wijaksana. China-made bekisting presence in Indonesia with low prices become a challenge for PT. Beton Perkasa Wijaksana. Therefore, companies should determine and re-evaluate the competitive strategy of construction firms in the business world today.
\end{abstract}

There are three objectives of this study. First, to determine the strength of the product PERI PT. Beton Perkasa Wijaksana in bekisting sales market share in Indonesia. Second, to determine what factors are the strength and the weaknesses of the company. Third, create business competition strategy for PT. Beton Perkasa Wijaksana.

SWOT method focuses on the IFE and EFE measurements to determine the current condition of the company and where the current level PT. Beton Perkasa Wijaksana. Formulated a strategy which will be constructed by the method of Bussiness Model Canvas which consists of nine pieces that reflect the company's box, where the BMC will look grouping of strategies that will be built in any part of it that exist in the company, which all the box will be connected to each other and have a relationship that will make strategies that can be applied.

Keywords: Formwork, SWOT, IFE, EFE, Bussiness Model Canvas.

\section{PENDAHULUAN}

Bersaing dalam kondisi persaingan bisnis modern, perusahaan dihadapkan pada kondisi lingkungan bisnis yang semakin tidak dapat diprediksi dan sangat dinamis. Kondisi perekonomian dan bisnis relatif stabil dan dapat diprediksi telah berubah menjadi penuh ketidakpastian, semakin kompleks, dan cepat berubah. Batas-batas antar negara cenderung hilang baik dari segi investasi, operasi industri, maupun informasi, dan mengarah pada internasionalisasi dan globalisasi perekonomian. Globalisasi memberikan tantangan bagi perusahaan yang terlibat di dalamnya, tetapi di sisi lain globalisasi juga memberikan peluang bagi perusahaan-perusahaan yang beroperasi di dalamnya.

Penelitian dilakukan di PT. Beton Perkasa Wijaksana untuk mengetahui secara internal (kondisi perusahaan) maupun secara eksternal (kondisi pesaing-pesaing dari perusahan yang sejenis). Dimana fenomena yang terjadi pada saat ini dapat dilihat dengan jelas dalam grafik penjualan pertahun dimana posisi PT. BPW ada di peringkat ke dua setelah PT. Cape East dalam kurun waktu 3 (tiga) tahun terakhir (gambar 1).

Untuk dapat memenangkan persaingan bisnis, perusahaan harus memiliki kinerja bisnis yang lebih baik dibandingkan para pesaingnya. Kinerja bisnis yang baik akan tercapai bila perusahaan mampu memposisikan dirinya dalam industri dan mempertahankan posisinya tanpa 
mengabaikan pengaruh perubahan lingkungan bisnis. Untuk itu pilihan dan implementasi strategi yang tepat akan sangat menentukan keberhasilan perusahaan.

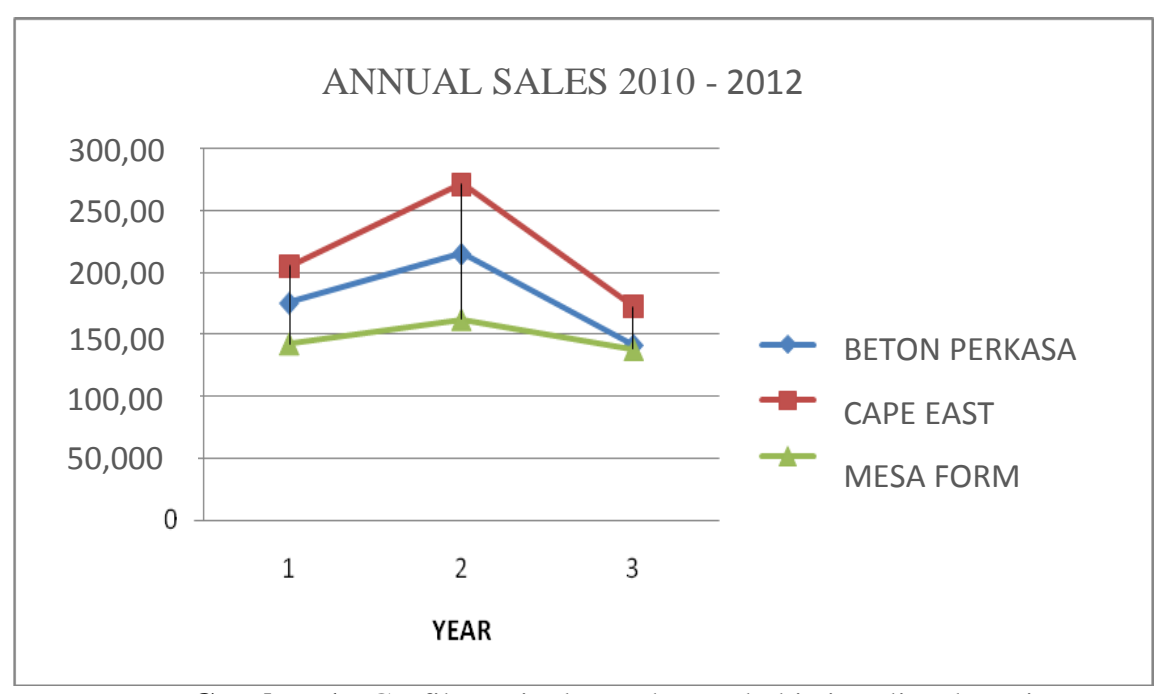

Gambar 1. Grafik Penjualan Tahunan bekisting di Indonesia

\section{METODE PENELITIAN}

Metodologi penelitian merupakan serangkaian tahapan penelitian yang harus diterapkan terlebih dahulu sebelum melakukan perumusan masalah sampai dengan penarikan kesimpulan dari permasalahn yang diteliti. Hal ini bertujuan agar memperjelas dan mempermudah jalannya penelitian dan agar penelitian yang dilakukan dapat lebih terarah dan tidak menyimpang dari tujuan yang diharapkan.

Agar penelitian tersebut dapat menghasilkan hasil yang memuaskan maka tiap tahapannya harus dilakukan dengan cermat karena setiap tahap merupakan bagian yang menentukan tahap selanjutnya. Dalam bab ini akan diuraikan mengenai langkah - langkah atau kerangka berpikir yang ditempuh dalam melakukan penelitian dan pemecahan masalah.

\section{HASIL DAN PEMBAHASAN}

\section{Perhitungan Skor setiap variabel untuk matriks IFE}

Setelah mendapatkan nilai bobot dan rating dari setiap faktor internal baik berupa kekuatan dan kelemahan perusahaan, maka langkah selanjutnya yaitu menghitung nilai skor dari tiap variabel tersebut dengan cara mengalikan nilai bobot dan rating tiap variabel sehingga akan menghasilkan total skor dari keseluruhan variabel untuk matriks IFE.

Tabel. 1. Faktor Strategis Internal PT. Beton Perkasa Wijaksana

\begin{tabular}{|c|c|c|c|}
\hline Key Internal Factors & \multirow[t]{2}{*}{ Bobot } & \multirow[t]{2}{*}{ Rating } & \multirow[t]{2}{*}{ Skor } \\
\hline Kekuatan (Strengths) & & & \\
\hline Merupakan pelopor Bekisting sistem pertama di Indonesia sejak tahun 1983 & 0.097 & 3.4 & 0.330 \\
\hline $\begin{array}{l}\text { Mempunyai merek dagang 'PERI' sudah dikenal oleh masyarakat konstruksi, } \\
\text { khususnya kontraktor dan konsultan kontruksi }\end{array}$ & 0.072 & 3.6 & 0.258 \\
\hline $\begin{array}{l}\text { Pelayanan terhadap konsumen dijaga, dalam hal ini Beton Perkasa memberikan service } \\
\text { dengan memberikan jasa engineering dan supervisi dengan baik untuk memenuhi } \\
\text { kebutuhan para kontraktor atas bekisting sistem yang handal. }\end{array}$ & 0.059 & 3.6 & 0.213 \\
\hline $\begin{array}{l}\text { Komitmen atas industri yang mengedepankan mutu, hal ini diketahui dari sertifikat ISO } \\
\text { yang telah didapatkan oleh Beton Perkasa yaitu ISO 9001:2000 }\end{array}$ & 0.089 & 3.4 & 0.301 \\
\hline $\begin{array}{l}\text { Adanya pelatihan-pelatihan kepada karyawan, baik yang di selenggarakan oleh internal } \\
\text { maupun eksternal }\end{array}$ & 0.072 & 3.6 & 0.258 \\
\hline
\end{tabular}


Tabel. 1. Faktor Strategis Internal PT. Beton Perkasa Wijaksana (lanjutan)

\begin{tabular}{|c|c|c|c|}
\hline Key Internal Factors & \multirow[t]{2}{*}{ Bobot } & \multirow[t]{2}{*}{ Rating } & \multirow[t]{2}{*}{ Skor } \\
\hline Kekuatan (Strengths) & & & \\
\hline $\begin{array}{l}\text { Jenjang karir yang berkesinambungan bagi seluruh karyawan PT Beton Perkasa } \\
\text { Wijaksana (BPW) }\end{array}$ & 0.076 & 3.6 & 0.273 \\
\hline $\begin{array}{l}\text { Satu-satunya perusahaan bekisting di Indonesia yang mampu memproduksi semua } \\
\text { sistem dan materi bekisting untuk kebutuhan lokal dan eksport internasional dengan } \\
\text { memproses } 6500 \text { ton komponen baja per tahun }\end{array}$ & 0.084 & 4.0 & 0.338 \\
\hline $\begin{array}{l}\text { Mempunyai Standar Operation Procedure (SOP) yang jelas untuk setiap pengerjaan } \\
\text { produksi di pabrik. }\end{array}$ & 0.080 & 3.4 & 0.273 \\
\hline \multicolumn{4}{|l|}{ Kelemahan (Weakness) } \\
\hline $\begin{array}{l}\text { Tingkat ketidaktersediaan material yang sangat tinggi sehingga mempengaruhi sirkulasi } \\
\text { kebutuhan matrial per proyek.. }\end{array}$ & 0.089 & 4.0 & 0.354 \\
\hline $\begin{array}{l}\text { Mempunyai harga bekisting sistem yang tinggi dipasaran dibandingkan dengan } \\
\text { bekisting sistem lain. }\end{array}$ & 0.076 & 4.0 & 0.304 \\
\hline $\begin{array}{l}\text { Birokrasi yang kompleks yang harus dilengkapi oleh customers sebelum pengambilan } \\
\text { matrial }\end{array}$ & 0.072 & 3.4 & 0.244 \\
\hline $\begin{array}{l}\text { kurangnya peran bagian QC terhadap investigasi matrial layak pakai yang } \\
\text { menyebabkan matrial tidak layak pakai masi digunakan }\end{array}$ & 0.063 & 3.6 & 0.228 \\
\hline $\begin{array}{l}\text { Tidak tersedia nya divisi ekspedisi untuk pengiriman matrial, yang menyebabkan } \\
\text { matrial di ambil sendiri oleh pihak customers }\end{array}$ & 0.072 & 3.6 & 0.258 \\
\hline TOTAL & 1.00 & & 3.632 \\
\hline
\end{tabular}

Total keseluruhan dari tabel tersebut didapatkan dengan menjumlahkan semua skor yang termasuk dalam faktor internal perusahaan.

\section{Eksternal Factor Evaluation}

1) Pembobotan Matriks EFE

$1=$ Sangat tidak mempengaruhi

2 = Tidak mempengaruhi

$3=$ Rata - rata

4 = Mempengaruhi

5 = Sangat mempengaruhi.

Tabel 2. Perhitungan Jawaban Bobot Untuk Matriks EFE

\begin{tabular}{|c|c|c|c|c|c|c|c|c|}
\hline \multirow[t]{2}{*}{ Responden } & \multicolumn{3}{|c|}{ Kesempatan (Opportunities) } & \multicolumn{4}{|c|}{ Ancaman (Threats) } & \multirow[t]{2}{*}{ Total } \\
\hline & 01 & $\mathbf{O 2}$ & $\mathbf{O 3}$ & T1 & $\mathbf{T} 2$ & T3 & $\mathbf{T 4}$ & \\
\hline $\mathrm{R} 1$ & 3 & 4 & 5 & 5 & 2 & 5 & 3 & 27 \\
\hline $\mathrm{R} 2$ & 5 & 3 & 3 & 2 & 3 & 5 & 4 & 25 \\
\hline R3 & 4 & 3 & 4 & 2 & 2 & 3 & 3 & 21 \\
\hline $\mathrm{R} 4$ & 3 & 3 & 2 & 3 & 2 & 4 & 3 & 20 \\
\hline $\mathrm{R} 5$ & 3 & 5 & 3 & 4 & 5 & 4 & 4 & 28 \\
\hline Total & 18 & 18 & 17 & 16 & 14 & 21 & 17 & 121 \\
\hline Bobot & 0.149 & 0.149 & 0.140 & 0.132 & 0.116 & 0.174 & 0.140 & 1.000 \\
\hline$\%$ & 14.88 & 14.88 & 14.05 & 13.22 & 11.57 & 17.36 & 14.05 & \\
\hline
\end{tabular}


contoh perhitungan :

1. Untuk kesempatan 1 (Opportunities 1)

- Jumlah responden : 5 orang

- Jumlah jawaban $\mathrm{O} 1=\mathrm{R} 1+\mathrm{R} 2+\mathrm{R} 3+\mathrm{R} 4+\mathrm{R} 5=3+5+4+3+3=18$

- $\quad$ Total jawaban R1 sampai dengan R5 = 121

- $\quad$ Bobot $\mathrm{O} 1=18 / 121=0.149$

- $\%$ Bobot $=0.149 \times 100 \%=14.88 \%$

2. Untuk Ancaman 1 (Threats 1)

- Jumlah responden $=5$ orang

- Jumlah jawaban $\mathrm{T} 1=\mathrm{R} 1+\mathrm{R} 2+\mathrm{R} 3+\mathrm{R} 4+\mathrm{R} 5=5+2+2+3+4=16$

- $\quad$ Total jawaban R1 sampai dengan R5 = 121

- $\quad$ Bobot $\mathrm{T} 1=16 / 121=0.132$

- $\%$ Bobot $=0.132 \times 100 \%=13.22 \%$

2) Penilaian Rating ( Rank ) Matriks EFE

Skala pemberian nilai rating pada matriks EFE (Peluang) yaitu :

1 = Sangat tidak baik

2 = Tidak baik

3 = Cukup baik

4 = Baik

5 = Sangat baik

Skala pemberian nilai rating pada matriks EFE (Ancaman) yaitu :

5 = Sangat tidak baik

4 = Tidak baik

3 = Cukup baik

$2=$ Baik

1 = Sangat baik

Tabel 3. Perhitungan Jawaban Rating Untuk Matriks EFE

\begin{tabular}{|c|c|c|c|c|c|c|c|}
\hline \multirow{2}{*}{ Responden } & \multicolumn{4}{|c|}{ Kesempatan (Opportunities) } & \multicolumn{4}{c|}{ Ancaman (Threats) } \\
\cline { 2 - 8 } & O1 & O2 & O3 & T1 & T2 & T3 & T4 \\
\hline R1 & 3 & 5 & 3 & 3 & 3 & 3 & 3 \\
\hline R2 & 3 & 5 & 5 & 4 & 4 & 5 & 4 \\
\hline R3 & 2 & 5 & 4 & 5 & 5 & 4 & 3 \\
\hline R4 & 2 & 5 & 3 & 3 & 3 & 2 & 4 \\
\hline R5 & 3 & 4 & 5 & 2 & 5 & 4 & 4 \\
\hline Total & 10 & 20 & 15 & 15 & 15 & 14 & 14 \\
\hline Jumlah & 5 & 5 & 5 & 5 & 5 & 5 & 5 \\
\hline Rating & $\mathbf{2 . 0}$ & $\mathbf{4 . 0}$ & $\mathbf{3 . 0}$ & $\mathbf{3 . 0}$ & $\mathbf{3 . 0}$ & $\mathbf{2 . 8}$ & $\mathbf{2 . 8}$ \\
\hline
\end{tabular}


1. Untuk kesempatan 1 (Opportunities 1)

- Jumlah responden : 5 orang

- Jumlah jawaban $\mathrm{O} 1=\mathrm{R} 1+\mathrm{R} 2+\mathrm{R} 3+\mathrm{R} 4+\mathrm{R} 5=3+3+2+2+3=10$

- $\quad$ Rating $\mathrm{S} 1=10 / 5=2.0$

2. Untuk Ancaman 1 (Threats 1)

- Jumlah responden : 5 orang

- Jumlah jawaban $\mathrm{T} 1=\mathrm{R} 1+\mathrm{R} 2+\mathrm{R} 3+\mathrm{R} 4+\mathrm{R} 5=3+4+5+3+2=15$

- $\quad$ Rating $\mathrm{S} 1=15 / 5=3$

\section{Perhitungan skor tiap variable untuk matriks EFE}

Setelah mendapatkan nilai bobot dan rating dari setiap faktor eksternal baik berupa peluang dan ancaman perusahaan, maka langkah selanjutnya yaitu menghitung nilai skor dari tiap variabel tersebut dengan cara mengalikan bobot dan rating tiap variabel sehingga akan menghasilkan total skor dari keseluruhan variabel untuk matriks EFE.

Tabel. 4. Faktor Strategis Eksternal PT. Beton Perkasa Wijaksana

\begin{tabular}{|l|c|c|c|}
\hline \multicolumn{1}{|c|}{ Key Eksternal Factors } & Bobot & Rating & Skor \\
\hline \multicolumn{1}{|c|}{ Kesempatan (Opportunities) } & 0.149 & 2.0 & 0.298 \\
\hline $\begin{array}{l}\text { Masih besarnya pangsa pasar bekisting sistem di Indonesia, khususnya pada } \\
\text { konstruksi gedung bertingkat, factory, dan pekerjaan infrastruktur }\end{array}$ & 0.149 & 4.0 & 0.595 \\
\hline $\begin{array}{l}\text { Masih sedikitnya para kontraktor dengan grade menengah yang menggunakan } \\
\text { bekisting sistem untuk proyek proyek mid rise building }\end{array}$ & 0.140 & 3.0 & 0.421 \\
\hline $\begin{array}{l}\text { Masih terbuka nya kesempatan untuk masuk ke pasar pasar di kota besar selain } \\
\text { di pulau jawa, yang mana cabang perwakilan Beton Perkasa hampir menyebar } \\
\text { seluruh Indonesia }\end{array}$ & & & \\
\hline $\begin{array}{l}\text { Ancaman (Threats) } \\
\text { Kondisi pasar yang fluktuatif, diakibatkan masuknya para pesaing dan produk } \\
\text { cina yang jauh lebih murah }\end{array}$ & 0.132 & 3.0 & 0.397 \\
\hline $\begin{array}{l}\text { Kurang adanya inovasi untuk menciptakan bekisting sistem menjadi lebih } \\
\text { effisien dengan biaya produksi yang lebih murah. }\end{array}$ & 0.116 & 3.0 & 0.347 \\
\hline $\begin{array}{l}\text { Produk competitor yang menawarkan desain yang lebih bagus, simple dan } \\
\text { menarik dengan harga yang lebih murah serta kemudahan sistem administrasi }\end{array}$ & 0.174 & 2.8 & 0.486 \\
\hline $\begin{array}{l}\text { Masih kurangnya koordinasi antara bagian marketing, warehouse dan QA } \\
\text { terhadap keluhan pelanggan terhadap performa produk }\end{array}$ & 0.140 & 2.8 & 0.393 \\
\hline TOTAL & $\mathbf{1 . 0 0}$ & & $\mathbf{2 . 9 3 7}$ \\
\hline
\end{tabular}

\section{Penerapan Strategi Bersaing Dengan Metode Kanvas Model Bisnis}

\section{Customer Segment}

Sasaran pelanggan PT. Beton Perkasa Wijaksana adalah para perusahaan kontraktor di Indonesia yang bergerak di bidang konstuksi gedung (high rise building, middle rise building, low rise building), konstruksi jembatan (civil work), konstruksi bangunan pabrik, akses platform, dengan kata lain dimana kontraktor yang membutuhkan cetakan beton yang mana jika dalam suatu pembangunan memerlukan konstruksi beton bertulang dan cor beton, itu merupakan pelanggan dari PT. Beton Perkasa Wijaksana selaku perusahaan yang bergerak di bidang bekisting atau cetakan beton yang menggunakan sistem PERI, sehingga pekerjaan cor beton menjadi tersistematis dengan baik. 
Pada saat ini tidak ada nya klasifikasi mengenai karakter pekerjaan yang di kerjaan oleh pelanggan, hanya berdasarkan perusahaan kontraktor saja tanpa melihat ruang lingkup pekerjaan yang dikerjakannya, sedangkan dalam dunia konstruksi terdapat beberapa lingkup pekerjaan konstruksi, antara lain pekerjaan gedung tinggi, sipil infrastruktur seperti jalan dan jembatan, gedung tidak tinggi, gedung pabrik, yang kesemuanya memiliki karakter dan penanganan yang berbeda terutama untuk lingkup pekerjaan bekistingnya. Dan saat ini pekerjaan tersebut tidak ada penanganan yang terpisah, semua dijadikan satu hanya berdasarkan pelanggan saja yang berdampak terhadap perlakuan dan penanganan pekerjaan serta tim yang menanganinya.

\section{Strategi yang harus dikembangkan berdasarkan analisis SWOT.}

Berdasarkan hasil analisis yang telah dilakukan terhadap lingkungan internal dan eksternal dari PT. Beton Perkasa Wijaksana maka dicoba untuk penerapan berdasarkan hasil analisis tersebut, antara lain :

Menurut SWOT untuk matriks SO (Strengths - Opportunities), strategi yang harus diterapkan oleh PT. Beton Perkasa Wijaksana adalah :

\section{Memperluas pangsa bekisting model LICO dengan kualitas yang bagus.}

PT. Beton Perkasa Wijaksana adalah satu-satunya produsen Bekisting LICO di Indonesia yang mampu membuat bekisting dengan konsep Man Handling (tidak perlu alat angkat). Adapun produksi dan penjualan bekisting LICO ini dari tahun 2010-2012 dapat dilihat pada table 4.18

Jika dilihat pada tabel, bisa dilihat bahwa pada tahun 2011, bekisting LICO dengan konsep man handling mempunyai produksi yang sangat tinggi dibandingkan dengan produksi pada tahun 2010 dan 2012.

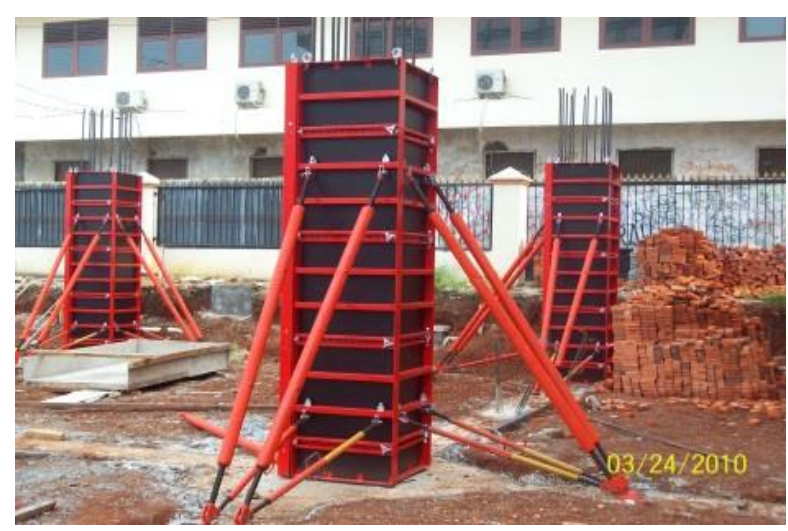

Gambar 5. Aplikasi Bekisting LICO untuk bangunan rendah

Bekisting LICO aplikasi penggunaanya banyak diaplikasikan pada bangunan low and middle rise building, sehingga produk PERI jenis LICO ini unggul pada daerah yang dimana para penggunanya adalah mayoritas kontraktor kelas menengah kebawah.

\section{Membuat informasi atau iklan kepada masyarakat mengenai produk PERI Beton} Perkasa

Tidak dapat dipungkiri bahwa tugas manajemen untuk membuat iklan untuk memberikan informasi mengenai produk PERI Beton Perkasa kepada masyarakat sangat kurang sekali. Memang pada saat ini, mediasi penyampaian informasi produk PERI Beton Perkasa hanya dilakukan dari mulut ke mulut per kontraktor pelaksana dikarenakan PERI Beton Perkasa adalah pelopor pembuatan bekisting sistem pertama di Indonesia sejak tahun 1983. Namun pada saat ini hal tersebut sudah dapat dikatakan ketinggalan jaman, 
dikarenakan mediasi dengan cara tersebut tidak sampai menyentuh segala lapisan masyarakat.

Apabila dilakukan pemberian informasi kepada masyarakat melalui media massa seperti televisi, radio dan surat kabar, serta melakukan promosi dan pelatihan-pelatihan di lingkungan universitas dengan mengkhusukan untuk teknik arsitek dan teknik sipil, akan menghasilkan brand image di para lulusan alumni fakultas tersebut sehingga diharapkan ketika para lulusan tersebut terjun di dunia kerja, sudah paham dan mengenal produk dan sistem bekisting PERI Beton perkasa untuk dapat di aplikasikan kedalam proyeknya dan akan membuat dari segala lapisan akan mengetahui dengan baik produk-produk yang dihasilkan oleh Beton Perkasa.

Menurut SWOT untuk matriks WO (Weakness - Opportunities), strategi yang harus dterapkan oleh PT. Beton Perkasa Wijaksana adalah :

\section{Pelatihan Sumber Daya Manusia dari tingkat operator sampai dengan manajemen secara terus menerus.}

PT. Beton Perkasa Wijaksana, memang secara rutin mengirimkan personel untuk mengadakan training di PERI pusat di Jerman. Namun hal tersebut bukan menjadi suatu jaminan hal tersebut bisa diterapkan di Indonesia. Hal tersebut dikarenakan selain kurangnya sebagian besar karyawan Beton Perkasa terhadap penguasaan bahasa asing, khusunya Jerman dan Inggris, selain itu system produksi antara PERI Jerman dengan PERI Beton Perkasa juga berbeda. Pada saat ini sistem produksi PERI Jerman menganut system produksi Pull System, dikarenakan selain kapasitas produksi yang besar dan dilengkapi dengan mesinmesin yang modern dan sistem-sistem operasi dan informasi yang digunakan disana adalah sistem operasi dan informasi yang paling terbaru, seperti ERP, sedangkan PERI Beton Perkasa masih mengandalkan push system dikarenakan kapasitas produksi yang masih sedikit juga masih kurangnya sumber daya manusia dalam penguasaan teknologi.

Pada saat ini pun, PT. Beton Perkasa Wijaksana tidak ada kebijakan untuk memberikan bantuan perkuliahan kepada para karyawannya. Padahal apabila hal tersebut dilakukan, maka hal tersebut dapat menjadi suatu investasi jangka panjang, dikarenakan selain karyawan merasa dihargai, sehingga menimbulkan rasa loyalitas yang tinggi terhadap perusahaan, pemahaman karyawan terhadap suatu permasalahan dan penguasaan terhadap teknologi pun akan semakin terasah.

\section{Harga Kompetitif dan Design yang Fleksibel.}

Dari gambar 1.2 dapat kita simpulkan bahwa dari segi penjualan bahwa PERI Beton Perkasa mempunyai harga yang relatif mahal dibandingkan dengan Cape East dan Produk china, sehingga pemakai lebih memilih Cape East atau produk china sebagai pilihan utama mereka dalam memilih bekisting sistem. Pemakai bisa mendapatkan kualitas yang bagus dengan harga yang murah dibandingkan dengan bekisting PERI Beton Perkasa, yang mempunyai kualitas yang bagus namun harga yang mahal. Dari data - data dari tabel tersebut juga kita ketahui bahwa masyarakat Indonesia cenderung memilih kualitas yang bagus dibandingkan dengan harga yang murah namun tidak memiliki kualitas yang bagus.

Harga produk PERI Beton Perkasa bisa tinggi dikarenakan beberapa hal yaitu :

1) Merupakan produk yang mempunyai tingkat kehandalan yang paling tinggi dibandingkan dengan produk-produk dari para kompetitornya.

2) Kurang adanya pembuatan design yang fleksibel, yang mampu meminimalkan komponen-komponen bekisting PERI, sehingga dapat menghasilkan produk yang lebih effisien namun tidak mengurangi mutu produk tersebut.

Produk PERI Beton Perkasa sangat terkenal akan kehandalannya, bahkan pada saat krisis ekonomi yang melanda Indonesia, pada tahun 1998, yang mengakibatkan harga BBM semakin meninggi. Pada saat sekarang ini PT. Beton Perkasa Wijaksana sedang melakukan penelitian terhadap salah satu matrial. Sehingga diharapkan kedepannya, PT Beton Perkasa Wijaksana bisa menciptakan suatu produk dan tidak lagi bergantung dari import matrial dari PERI Jerman. 
Menurut SWOT untuk matriks ST (Strengths - Threats), strategi yang harus dterapkan oleh PT. Beton Perkasa Wijaksana adalah :

\section{Meningkatkan produktivitas dan effisiensi kerja}

Adapun strategi Strengths - Threats yang harus diterapkan oleh PT. Beton Perkasa Wijaksana adalah meningkatkan produktivitas dan effisiensi kerja. Pada saat ini, masalah yang paling sering terjadi adalah kurang koordinasi antara tiap departemen di PT. Beton Perkasa Wijaksana dalam merespon suatu permasalahan sehingga permasalahan tidak cepat ditangani dengan baik. Hal tersebut secara otomatis akan mengurangi tingkat effisiensi dalam bekerja.

Klaim yang sering diresponnya dengan telat adalah apabila terjadi klaim dari pelanggan. Pada umumnya klaim yang sering dimunculkan adalah masalah komponen yang tidak lengkap dalam pengiriman ke lokasi proyek. Hal tersebut sangat mempengaruhi jumlah input yang semakin besar dengan output tetap sehingga indeks produktivitas semakin menurun.

Adapun cara-cara untuk meningkatkan produktivitas dan effisiensi kerja dengan kaitannya untuk mengurangi klaim dari konsumen PT. Beton Perkasa Wijaksana adalah :

1) Harus diadakan rapat koordinasi secara terus menerus antara tiap department di PT. Beton Perkasa Wijaksana untuk memecahkan segala permasalahan yang ada.

2) Selain diadakan rapat secara internal, PT. Beton Perkasa Wijaksana juga seharusnya harus berani mengambil inisiatif untuk turun langsung ke pengecekan ketika matrial siap dikirim.

Menurut SWOT untuk matriks WT (Weakness - Threats), strategi yang harus dterapkan oleh PT. Beton Perkasa Wijaksana adalah :

\section{Peningkatan Kualitas Produk dan Pengiriman Material}

Peningkatan kualitas produk yang dihasilkan dan pengiriman material ke lokasi proyek merupakan fokus strategi yang hadus diterapkan di PT. Beton Perkasa kedepannya. PT. Beton Perkasa mempunyai ciri khas yang hampir sama dengan industri bekisting lainnya, baik sistem produksi maupun komponen - komponen material yang akan dirakit menjadi sebuah mesin bekisting sistem yang mana proses perakitannya dilokasi proyek. Atas dasar tersebut, PT. Beton Perkasa mencoba menerapkan perakitan bekisting dilakukan di workshop Beton perkasa dan dikirim ke pelanggan sudah terpasang, sehingga pelanggan akan terbantu dengan menghilangkan biaya produksi perakitan bekisting sistem PERI diproyeknya, dengan konsep produk datang lalu langsung pasang. Selain itu pengawasan terhadap matrial tidak layak pakai atau pun cacat dapat terpantau dengan baik, sehingga tidak lagi ada matrial yang rusak yang terkirim ke pelanggan. Namun hal ini juga harus dipertimbangkan dengan kapasitas pekerja di PT. Beton Perkasa itu sendiri, khususnya yang menangani perakitan tersebut, hal ini menjadi sebuah pemikiran untuk menambah kapasitas lahan maupun pekerja.

\section{Strategi berdasarkan Bussiness Model Canvas.}

\section{Strategi di Panggung Depan (Front Stage)}

Dalam penerapan strategi berdasarkan Bussiness Model Canvas yang harus diperhatikan adalah keterkaitan antar kotak (block). Perubahan pada satu kotak akan berdampak pada kotakkotak lainnya. Sebagai contoh perubahan pada Customer Segment akan mempengaruhi kotak Value Propositions yang ditawarkan, dan juga kotak-kotak lainnya. Hal ini yang terjadi ketika PT. Beton Perkasa hanya memfokuskan pada segmen kontraktor secara global, ketika segmentasi pelanggan dipertajam lagi maka menyebabkan PT. Beton Perkasa harus mendefinikan ulang Value Propositions yang ditawarkan (gambar 4.13).

Perubahan pada value propositions ini juga berdampak pada key activities yang mana semua pihak harus memfokuskan terhadap pemenuhan kebutuhan pelanggan yang tepat waktu dan tidak terbebani dengan pelanggan harus mengambil sendiri matrialnya, dalam hal ini pihak Beton Perkasa memonitoring langsung matrialnya.

Key resources pun juga terkena dampak, untuk memenuhi value propositons yang dijanjikan, Beton Perkasa harus memperkuat di lini engineering untuk dapat menyajikan sistem 
yang terbaik bagi pelanggan, selain itu kapasitas lahan dan produksi untuk mendukung kebutuhan matrial sistem amat lah penting sehingga tidak terjadi kekosongan matrial ketika pelanggan membutuhkan.

Untuk memperoleh Value Propositions yang tajam serta tepat sasaran, maka Customer Segment yang dilayani perlu dipecah dengan lebih spesifik lagi. Dari bisnis model yang baru terlihat bahwa kontraktor dibagi menjadi kontraktor gedung dan kontraktor sipil dengan demikian membutuhkan penanganan yang berbeda sesuai dengan karakternya masing-masing sehingga ini yang perlu dijadikan value propositions. Dan diharapkan value propositons yang ditawarkan Beton Perkasa merupakan sebuah jawaban atas keinginan pelanggan yang mengharapak kemudahan dalam pelaksanaan proyeknya, khususnya untuk lingkup pekerjaan bekisting sistem.

Runtutan berikutnya adalah perluanya Customers Segment ini mendapatkan informasi melalu Channel yang aktif, dalam hal ini Beton Perkasa menggunakan Channel langsung untuk mengkomunikasikan value propositions yang ditawarkan oleh Beton Perkasa, sehingga pelanggan akan langsung mendapatkan informasi perihal apa yang menjadi keunggulan Beton Perkasa.

\section{Strategi di Panggung Belakang (Back Stage)}

Kalau panggung depan (front stage) berintikan pemenuhan harapan dari setiap Customer Segments, maka panggung belakang (Back Stage) harus sangat kuat agar janji yang diberikan Beton Perkasa pada Customer Segment dapat diwujudkan dengan baik, key activities berupa riset dan pengembangan dari metode kerja bekisting sistem yang dimiliki Beton Perkasa perlu ditingkatkan lagi agar value propositions bagi setiap segmen pelanggan dapat diwujudkan dengan baik. Demikian juga pelatihan-pelatihan terhadap sumber daya manusia yang dimiliki Beton Perkasa dibidang teknik dan manajemen perlu juga ditingkatkan. Selain itu, kemitraan dengan Key Partners seperti kontraktor, konsultan konstruksi dan lembaga pendidikan tinggi perlu ditingkatkan guna menciptakan brand image yang harapan kedepannya tercipta hubungan erat dan keterkaitan dalam pekerjaan yang sesuai dengan apa yang Beton Perkasa tujukan.

Salah satu hal yang perlu dipertimbangkan adalah bertambahnya biaya untuk melakukan riset untuk pengembangan bahan juga pengembangan pelayanan dalam hal ini adalah ekspedisi yang mengantarkan matrial kebutuhan pelanggan ke lokasi dimana proyek dari pelanggan itu berada, meskipun tambahan kegiatan ini mutlak diperlukan guna meningkatkan manfaat dari pelayanan yang diberikan. Selain itu, tambahan biaya depresiasi dari lahan, alat produksi dan armada perlu diperhitungkan, meskipun keberadaan hal tersebut merupakan potensi tambahan pendapatan ataupun penilaian baik dari pelanggan.

Bisnis model yang coba diterapkan di PT. Beton Perkasa ini guna menciptakan strategi bersaing yang handal untuk dapat memimpin pasar bekisting yang ada, untuk itu konsep ValueDriven sasaran utamanya adalah kepuasan pelanggan dan menciptakan citra Beton Perkasa dimata para pelanggannya sebagai perusahaan yang memberikan banyak nilai tambah untuk proyeknya, untuk itu efisiensi biaya tidak menjadi hal yang terlalu utama.

\section{KESIMPULAN DAN SARAN}

\section{Kesimpulan}

Berdasarkan hasil analisis data dan pembahasan pada bab sebelumnya, maka setelah dilaksanakan penelitian yang dilakukan di PT. Beton Perkasa Wijaksana terkait strategi bersaing yang akan coba diterapkan dengan menggunakan pengukuran IFE dan EFE dari metode SWOT dan juga membuat strategi tersebut menjadi lebih dinamis dengan menggunakan metode Bussiness Model Canvas sesuai dengan tujuan penelitian yang telah disampaikan diawal, sehingga dapat disimpulkan beberapa kesimpulan sebagai berikut:

1. Memperkuat pemasaran dan penetrasi pasar untuk produk bekisting PERI dengan type PERI LICO serta melakukan perbaikan-perbaikan terkait performa untuk produk tersebut guna dapat menjadi market leader untuk produk bekisting vertikal dengan kemudahan man handling. 
2. Promosi produk-produk Beton Perkasa lebih ditingkatkan, khususnya ke lembaga pendidikan tinggi khususnya teknik sipil guna menciptakan pola pikir pemakaian bekisting sistem khususnya PERI yang terdapat di Beton Perkasa.

3. Untuk mengatasi lemahnya tingkat kompetensi sumber daya manusia yang terdapat di Beton Perkasa, dan guna menjaga kualitas dan performa perusahaan, maka perlu adanya peningkatan kualitas dan kemampuan SDM yang ada di Beton Perkasa mulai dari level rendah sampai level tinggi dengan pelatihan-pelatihan mengenai teknik dan manajemen baik dari internal perusahaan maupun eksternal perusahaan.

4. Dari hasil pemaparan data yang ada dan mengacu hasil analisis SWOT serta melihat kondisi internal dan eksternal perusahaan, maka didapat strategi bersaing PT. Beton Perkasa dengan menggunakan 9 (sembilan) Block Bussiness Model Canvas yang terdiri dari kotak-kotak sebagai berikut :

- Customer Segment

- Kontraktor Bangunan Gedung

- Kontraktor Bangunan Sipil

- Value Propositions

- Hasil Cor yang mulus tanpa cacat.

- Optimalisasi penyediaan set bekisting

- Tercapainya ulang kali pemakaian bekisting yang optimal

- Channels

- Marketing engineer.

- Supervisi

- Ekspedisi \& Staff Logistik

- Customers Relationships

- Discount order

- Merchandise \& souvenir

- Customer Gathering

- Key Activities

- Follow Up proyek

- Disain dan estimasi metode kerja

- Monitoring kebutuhan matrial

- Key Resource
- Merek dagang PERI Jerman

- Lahan dan alat produksi yang

lengkap

- Tim Engineering yang handal

- Database prospek proyek yang

lengkap

- Key Partners

- Kontraktor Konstruksi

- Konsultan Kontruksi

- Lembaga pendidikan tinggi (Universitas \& Politeknik fakultas Sipil

- Revenue Streams

- Penjualan Bekisting dan plywood

- Penyewaan bekisting dan jasa supervisi

- Cost Structure

- Biaya tenaga kerja

- Biaya pemasaran

- Biaya ekspedisi

- Biaya over head

\section{Saran}

Merunut tujuan awal penelitian yang tersampaikan di bab awal, dimana pengukuran kekuatan produk dan mengetahui fakto-faktor kekuatan dan kelemahan Beton Perkasa, maka disarankan bagi PT. Beton Perkasa untuk lebih fokus terhadap kekuatan produk dan perubahan budaya kerjanya, dan berdasarkan hasil penelitian dimana penelitian ini masih dalam tahap usulan mengenai strategi bersaing yang dijabaran dalam Bussiness Model Canvas, maka diharapkan manajemen Beton Perkasa dapat mulai menerapkan dengan melihat tingkat prioritas dalam hal pelaksanaan dilapangannya untuk dapat menjadi evaluasi untuk penelitian selanjutnya.

\section{DAFTAR PUSTAKA}

Bateson, J., \& Hoffman, K. (1999). Managing Service Marketing: Text and Reading. Fort Worth: The Dryden Press.

Canon. (2008). Pemasaran Dasar. Jakarta: Salemba Empat.

David, F. R. (2006). Management Strategis : Konsep (10 ed.). Jakarta: Salemba Empat.

Ellitan, L., \& Anatan, L. (2008). Manajemen Strategis Operasi: Teori dan Riset Di Indonesia. Bandung: Alfabeta.

Gasperz , V. (1997). Manajemen Bisnis Total Dalam Era Globalisasi. Jakarta: Gramedia. 
Hayes, R., \& Schemmer, R. (1978). How Should You Organize Manufacturing. Harvard Bisnis Review.

Kim, W. C., \& Mauborgne, R. (2006). Startegi Samudra Biru (Blue Ocean Strategy). Jakarta: PT. Serambi Ilmu Sentosa.

Kotler, P., \& Amstrong, G. (2001). Prinsip-prinsip Pemasaran. Jakarta: Erlangga.

Manajemen, T. P. (2012). Bussiness Model Canvas; Penerapan di Indonesia. Jakarta: PPM.

Mintzberg, H. (1978). Pattern in Strategi Formulation. Management Sciences, 24(9).

Porter, M. E. (1994). Keunggulan Bersaing (Competitive Advantage)-Terjemahan. Jakarta: Binarupa Aksara.

Potter, M. E. (1993). Keunggulan Bersaing: Menciptakan Dan Mempertahankan Kinerja Unggul. Jakarta: Erlangga.

PT. Beton Perkasa Wijaksana. (Unpublished). Annual Production Report.

PT. Beton Perkasa Wijaksana. (Unpublished). Annual Sales Report .

PT. Beton Perkasa Wijaksana. (Unpublished). Standar Operation Procedure.

Rangkuti, F. (2008). Analisis SWOT Teknik Membedah Kasus Bisnis. Jakarta: Gramedia Pustaka Utama.

Tjiptono, F., \& Chandra, G. (2007). Service Quality \& Statisfaction. Yogyakarta: Penerbit Andi. 
